\title{
UN VOYAGE À TRAVERS LES IDÉES EN AMAZONIE AU XVIIIE SIĖCLE: LA CONDAMINE, TRADUÇÃO E CULTURA
}

\author{
Samuel Lucena de Medeiros ${ }^{1}$ \\ Tatiana de Lima Pedrosa Santos 1 \\ ${ }^{1}$ Universidade Estadual do Amazonas, Manaus, Amazonas, Brasil \\ Walter Carlos Costa ${ }^{2}$ \\ ${ }_{2}^{2}$ Universidade Federal do Ceará, Fortaleza, Ceará, Brasil
}

\begin{abstract}
Resumo: Este trabalho objetiva o diálogo entre História, Antropologia e Estudos da Tradução, com enfoque na Tradução Cultural. Para tal, parte-se do exemplo dos relatos deixados pelo cronista e viajante francês La Condamine, que expedicionou a Amazônia em finais da primeira metade do século XVIII, publicando seus registros quando de seu retorno ao continente europeu. Utiliza-se aqui recentes discussões, através das quais se torna possível entrever nos relatos indicações do uso da tradução cultural, em suas diferentes instâncias. Apresenta-se uma breve introdução, seguida de contextualização teórico-epistemológica e histórica concernente ao trabalho do cientista francês e sua figura científica. Aborda-se também a tradução cultural e como pode ser pensada, de forma a preparar o leitor para o próximo tópico, que entrecruzando as discussões anteriores, mostra exemplos de tradução cultural nos textos de La Condamine em várias manifestações, sejam elas idiomáticas, linguísticas ou etnocêntricas e das considerações finais. A partir da abordagem proposta e das discussões desenvolvidas, pode-se pensar em diferentes formas de leitura de registros históricos dos viajantes, destacando-se o potencial que apresentam para análises nos campos dos estudos culturais e tradutórios, dentre os quais os do autor analisado são ricos exemplos do contato com o "outro".
\end{abstract}

Palavras-Chave: Amazônia; Tradução Cultural; Literatura de Viagem; La Condamine. 


\title{
UN VOYAGE À TRAVERS LES IDÉES EN AMAZONIE AU XVIIIE SIĖCLE: LA CONDAMINE, TRANSLATION AND CULTURE
}

\begin{abstract}
This work aims the dialogue between History, Anthropology and Translation Studies, focusing on Cultural Translation. It is based on the accounts left by the French chronicler and traveller La Condamine, who expeditioned the Amazon at the end of the first half of the 18th century, publishing his records on his return to the European continent. We use discussions, through which it is possible to glimpse in the accounts indications of the use of cultural translation, in its different instances. After a brief introduction, we present a theoretical-epistemological and historical contextualization concerning the work of the French scientist and his scientific figure. We use also Cultural translation concepts in order to prepare the reader for the next topic, which shows examples of cultural translation in the texts of La Condamine in various manifestations, whether idiomatic, linguistic or ethnocentric. The proposed approach and the discussions carried out allow us to think of different ways of reading the historical records of travellers, highlighting their potential for analysis in the fields of cultural and translation studies, among which those of $\mathrm{La}$ Condamine are rich examples of contact with the "other".
\end{abstract}

Keywords: Amazon; Cultural Translation; Travel Literature; La Condamine

\section{Introdução}

Dos muitos viajantes-cronistas que passaram pelo Amazonas, tanto através de seu território político-administrativo quanto navegando pelo curso do lendário "Rio das Amazonas", ou seguindo pelas dinâmicas e múltiplas fronteiras da Amazônia, temos os registros da personalidade que, em meados do século XVIII, realizou, em seus cadernos, descrições únicas: tratamos aqui do francês La Condamine.

Muito presente na bibliografia do campo historiográfico, antropológico e etnológico indígena, como se vê em Aguiar (2009), torna possível através de seus registros múltiplas abordagens, já que sua escrita pode ser vinculada ao estilo dos filósofos naturais franceses de sua época. Assim, os apontamentos que hoje pode- 
riam ser considerados "transdisciplinares", figuram-se para além de simples fontes históricas, já que, por sua grande carga cultural, atraem a atenção para estudos diversos.

É considerando este cenário que o presente trabalho busca abordar de maneira interdisciplinar os registros do cronista francês. Utilizando contribuições da Etnohistória, Antropologia e Estudos da Tradução Cultural, propõe-se a entrever formas de (inter)tradução cultural na Amazônia em seus registros. Para isso, partimos dos escritos publicados ainda em seu tempo (La Condamine 1745) e da tradução disponibilizada pelo Senado Federal ${ }^{1}$ (La Condamine (b)). O fato desta tradução ter sido realizada por iniciativa do Senado reforça a relevância da tradução cultural de La Condamine para o conhecimento da Amazônia e do Brasil.

Entretanto, antes de apresentarmos as considerações resultantes deste diálogo, que também toca questões referentes aos conceitos desenvolvidos no longo processo de colonização, procedemos a uma contextualização histórica e epistemológica e a uma breve discussão teórica, seguida de exemplos concretos ilustrando aspectos sociológicos e culturais.

\section{La Condamine: o viajante que se tornou cronista}

Charles-Marie de La Condamine, nascido em Paris no ano de 1701, foi um dos muitos cronistas, viajantes e cientistas que se notabilizaram por seus trabalhos abrangentes acerca da América do Sul e Brasil. Isso ocorreu antes da virada dos séculos XIX-XX, desde os primeiros contatos do europeu no século XV e passando pelos períodos colonial e imperial, de acordo com as especificidades socioculturais de cada localidade e organização político-territorial.

O trabalho de La Condamine, desenvolvido entre as décadas de 1720 e 1770, foi um dos mais amplos do seu século, tendo es-

\footnotetext{
1 https://www2.senado.leg.br/bdsf/bitstream/handle/id/1045/580837.pdf?sequen $\mathrm{ce}=4 \&$ is Allowed $=\mathrm{y}$.
}

Cad. Trad., Florianópolis, v. 40, $\mathbf{n}^{0}$ 2, p. 16-37, mai-ago, 2020. 
crito sobre os assuntos mais diversos, da física à matemática e à astronomia (chamadas "ciências positivas"), à história natural e à medicina (La Condamine (b)). Onde ganhou maior reconhecimento entre os acadêmicos europeus, principalmente dos membros da Académie des Sciences de Paris, foi o concernente às suas expedições empreendidas ao ambiente amazônico.

Havia, no entanto, uma boa e forte razão para que um francês se pusesse a uma aventura no "Novo Mundo", distante do amparo e suporte das metrópoles europeias, tanto material quanto logístico em relação ao campo, e que ultrapassa a extrema curiosidade do e persistência do cientista, considerada por Basílio de Magalhães como pública e notória, mas também excessiva ou abusiva. O motivo eram os conflitos pelo controle da soberania política, territorial e econômica levados pela França de Luís XV, contrapondo-se especialmente à Grã-Bretanha, então a principal potência europeia.

Rival econômica da Grã-Bretanha, havia da parte francesa, como aponta Hobsbawm (2003), a vontade de superar o hiato que havia se formado em relação ao comércio quadruplicado da Grã -Bretanha, o que levou à aplicação de um sistema de colonização muito mais dinâmico que o britânico. Dessa forma, mesmo não sendo uma potência internacional, era, no entanto, uma velha aristocracia poderosa e autoritária, com com poderes de monarquia absolutista. Esses poderes, gerando em seu cerne tantos conflitos, acabou desaguando na Revolução Francesa, em 1789.

Dessa forma, para alcançar um patamar de uma (meta)potência, bem como para esclarecer noções primordiais suscitadas pela ciência iluminista, como a forma da Terra, a contagem do tempo, questões cartográficas, leis físicas, foram financiadas expedições a terras distantes da Europa, sendo numa delas a do antigo cavaleiro do exército francês, e cientista da Academia das Ciências de Paris, La Condamine às costas da África e da Ásia, em 1731.

Três grandes expedições foram organizadas pelo Conde de Maurepas, bisneto de Luís XIV, durante o século XVIII, tendo La Condamine participado da primeira, em 1735. Os passaportes foram concedidos por Felipe V (rei da Espanha e neto de Luís XIV), visto 
que teria como destino as terras ibero-americanas, partindo de La Rochelle em 16 de maio e chegando à costa do Peru um ano mais tarde, depois de passar pelo Istmo do Panamá (La Condamine (b)).

Mesmo acompanhado de outros cientistas, La Condamine ficou encarregado de registrar a viagem, pois já desfrutava da fama de bom escritor na França. Desta, resultaram três grandes publicações, sendo a primeira, de 1745, a que descreve o início da expedição e os preparativos da famosa descida do Rio Amazonas, onde, com ajuda de instrumentos sofisticados, realizou correções às anotações do Padre Samuel Fritz de 1691, propondo um novo mapa para a bacia do Amazonas. Foi publicada com o seguinte título: Relation abrégée d'un voyage dans l'intérieur de l'Amérique méridionale, depuis la côte de la mer du Sud jusqu'aux côtes du Brésil et de la Guiane, en descendant la rivière des Amazones Lue à l'assemblée publique de l'Académie des Sciences, le 28 avril 1745 - avec une carte du Maragnon ou de la rivière des Amazones, levée par le même.

Como poderia La Condamine, um astrônomo competente que passou a melhor parte de oito anos pesquisando três graus do meridiano, acreditar que poderia mapear o curso da Amazônia, estabelecendo vários pontos de latitude e longitude, em uma única passagem rápida dos Andes para o Atlântico? Ou a sua viagem era politicamente motivada ou não tinha noção da magnitude da sua tarefa. ${ }^{2}$ (Mcconnell 17).

O objetivo inicial de La Condamine era, além de registrar a viagem, medir a longitude de um grau do meridiano na linha equinocial.

2 "How could La Condamine, a competent astronomer who had spent the best part of eight years surveying three degrees of the meridian, believe that he could chart the course of the Amazon, establishing various points of latitude and longitude, in a single swift passage from the Andes to the Atlantic? Either his journey was politically motivated or he had no conception of the magnitude of his task." (Mcconnell 17). Tradução nossa, como das outras traduções sem indicação de tradutor.

Cad. Trad., Florianópolis, v. 40, no 2, p. 16-37, mai-ago, 2020. 
Porém, pedindo permissão ao governo português, pôs em prática seu curioso plano de descer o "rio-mar", entre 1743 e 1744. Partiu de Jaén de Bracamoros (Peru) e chegou em Belém do Pará, percorrendo o trajeto das nascentes à foz. Outros pormenores da descida foram acrescentados na segunda publicação, em 1751, intitulada: Journal du voyage fait, par ordre du Roi, à l'Equateur, servant d'introduction historique à la mesure des trois degrés du méridien.

La Condamine não explicita os motivos de inclusão ou exclusão dos aspectos abordados em seus relatos. Como costumavam fazer os cronistas do século XVIII, seus escritos da viagem à América abordam desde a botânica das espécies amazônicas, a química das substâncias que posteriormente seriam utilizadas pelas grandes indústrias europeias, a medicina tradicional regional, a descrição etnográfica e geográfica (história natural) de praxe, entre outros.

Cabe ressaltar que, àquela altura da consolidação das "ciências positivas" e das "ciências do homem", estas últimas, com destaque para a etnografia, tinham dificuldade para se impor, por estarem em um "estado de flutuação", como observa Clastres:

$\mathrm{O}$ traço mais marcante da etnografia teórica do século XVIII, se é possível caracterizá-la por um traço, é talvez uma certa solução de continuidade e, pode-se dizer, uma certa inércia: como se não houvesse história propriamente dita, ou como se ela não fosse cumulativa [...]. O exato oposto, consequentemente, do que vai caracterizar a etnologia um século depois, a saber, o 'estado de flutuação' [...], as noções tiveram de ser continuamente 'desfeitas e reconstruídas': enfim, tudo o que marca os começos da ciência e é indício do seu progresso (Clastres 188).

A bagagem teórica e as questões científicas de interesse de $\mathrm{La}$ Condamine deviam estar sintonizadas com as correntes etnográficas francesas, além dos conceitos empiristas das aplicações físico -matemáticas. Contudo, no que concerne à etnologia e à etnografia, podemos notar que, como seus coetâneos, seu interesse se con- 
centrava naqueles fenômenos que pareciam ser vestígios de algo inicial, anterior às formas "evoluídas", relacionados ao "homem semicivilizado", como dizia Van Gennep (1914).

Com um toque idiossincrásico do seu século, o de ver os "povos selvagens", "não-civilizados", como "povos primitivos", "isto é, primeiros: no começo de uma história que é a do gênero humano" (Clastres 190), La Condamine descreve a paisagem natural e cultural enquanto variação, possibilidade de alternância entre o contexto europeu e o dos trópicos. O "Homem" passa então a ser diretamente alvo da ciência, agora uma ciência humana. E é no trabalho dos naturalistas, como passaram a ser chamados os viajantes relatores, que as fórmulas, teorias, e hipóteses passam a ganhar embasamento, e serão consultados pelos estudiosos das novas gerações. $\mathrm{O}$ Conde de Buffon, Georges-Louis Leclerc, em 1749, ao escrever sobre história natural, destaca os pontos levados em consideração naqueles primeiros trabalhos, dentre os quais aparecem os de La Condamine, e que constituíam a base de noções sobre a espécie humana, antes mesmo de Darwin e dos antropólogos acadêmicos:

Originalmente, só houve uma espécie de homens que, tendo-se multiplicado e disseminado por toda a terra, sofreu diferentes mudanças por influência do clima, pela diferenciação da alimentação, da maneira de viver, das doenças epidêmicas, e também pela mistura variada ao infinito de indivíduos mais ou menos semelhantes [...]. A primeira e mais marcante dessas variedades [as dos homens de diferentes climas] é a da cor, a segunda é a da forma e do tamanho, e a terceira é a do natural dos diferentes povos (315, grifo nossos).

Os relatos e dados colhidos em campo pelos naturalistas e viajantes científicos passam a ser interpretados em modelos próprios, o que leva os estudiosos a dar um encaminhamento distinto, pois o estudo das características físicas e naturais do homem dão lugar ao estudo das características mentais e culturais. Contudo, estes estu- 
dos estavam intrinsecamente ligados, sem que a nova abordagem substituísse a anterior. Esta apenas veio dar utilidade aos dados antes coletados e acumulados nos abundantes tomos científicos. Portanto, "os caracteres pelos quais os homens, e as sociedades, se diferenciam, estão estritamente ligados; e mais: decorrem logicamente uns dos outros" (Clastres 192). Assim, o "feio" era também cruel, sem cultura e assim por diante. Acrescente-se a isto o olhar etnocêntrico e protoevolucionista, como se vê não poucas vezes nas descrições de La Condamine dos indígenas, os "selvagens".

Talvez para atender à cobrança dos acadêmicos franceses, ou mesmo como justificativa num momento de formação das ciências, La Condamine inicia os relatos explicando qual era seu objetivo principal, enfatizando a "seriedade" de seu trabalho de campo, dizendo que os detalhes de seus relatos da viagem que fugiam dos interesses físico-matemáticos ou geográficos, ou seja, os etnográficos e históricos, apenas foram registrados pela abundância de acontecimentos, mas que não constituíam o principal de seu trabalho (La Condamine (b)).

Não se sabe se essas justificativas introdutórias eram meras explicações para os veteranos franceses da antiga escola científica, que o apoiaram logística e financeiramente, ou se reflexos de um receio do autor em ser confundido com os aventureiros. $\mathrm{O}$ curioso é que dedicou as primeiras páginas de sua publicação a essa ênfase, sem saber que os relatos que considerava "secundários" seriam os que mais atrairiam interesse ao serem apresentados na França e igualmente em estudos posteriores.

Terminada a questão da configuração da Terra, e atenuada a curiosidade pública neste particular, cri interessar mais a assembleia pública de 26 de abril último, com uma relação de viagem pelo rio das Amazonas, que desci desde o ponto em que começa a ser navegável até a embocadura, percorrendo uma extensão de mais de mil léguas. Mas a abundância de assuntos não me permitiu encerrar-me nos limites prescritos à leitura; acharam-nos realmente acanhados, e 
fui obrigado a fazer acrescentamentos à medida que ia lendo [...] (La Condamine (b), 32).

La Condamine parece buscar apresentar-se como um "verdadeiro" cientista, aquele que pensa, vive e aplica a ciência de forma rígida, e que pouco se interessa pelas questões de estudo do homem. Suas palavras chegam ao ponto de pôr em patamares diferentes as ciências.

Para não iludir aqueles que num relato de viagem só procuram acontecimentos extraordinários e hábitos desconhecidos, devo advertir que esses aqui encontrarão, pouco do que se satisfaçam. Não tive a liberdade de fazer passear o leitor indiferentemente por todos os objetos apropriados a adular a sua curiosidade. [...] Aqui o que interessa é o levantamento da carta do curso de um rio que atravessa vastas regiões, quase desconhecidas de nossos geógrafos. Tratava-se de dar ideia disso numa memória destinada a ler-se na Academia das Ciências. Numa semelhante exposição, mais me preocupando instruir do que divertir, aquilo que não toca à geografia, à astronomia, ou à física começa a parecer digressão que afasta do meu objetivo [...] (La Condamine (b), 32, grifo nosso).

Essa imagem é contraditória, visto sua preocupação, ao longo do relato da viagem ao Rio Amazonas, em registrar os detalhes das questões culturais, versar sobre as questões que então entravam em voga nas ciências humanas.

[...] por outro lado não era justo que eu abusasse da paciência pública, lendo uma lista de nomes bárbaros de nações e rios, e um jornal de alturas do Sol e das estrelas, latitudes e longitudes, medidas, rotas, distância, sondagens, variações de bússola, experiências de barômetro etc. [...] Não registro aqui senão os fatos capitais, e a posição dos lugares mais notáveis, seguindo a ordem da narração. Tratei com 
algum desenvolvimento a questão das amazonas americanas, porque me pareceu que isso se esperava de mim. Introduzi entre as notas de física e história natural alguns fatos históricos, quando eles não me desviavam muito do assunto (La Condamine (b), 32-33, grifo nosso).

Há, entretanto, um ponto de ruptura em seu trabalho, que o destaca como, ainda que de forma pouco consciente, um marco nas mudanças de perspectiva, no que concerne às relações de campo, pesquisador-objeto e noção de respeito pelo que registra. La Condamine, ao citar termos e nomes indígenas, bem como nos termos portugueses e espanhóis, seguiu a ortografia conhecida para cada um em sua época, em contraposição à praxe dos cronistas, que transpunham para a ortografia de sua língua os termos nativos: "Eu quis assim evitar o inconveniente de os tornar irreconhecíveis aos autores originais" (La Condamine (b), 34).

O conflito do autor cronista na seleção dos fatos importantes e merecedores de registro, como o enfoque que deveria dar à sua narrativa, em que assunto deveria deter-se mais que em outro, dedicando mais palavras e pormenores, entre outros fatores, aparece em sua introdução ao relato. La Condamine mostra a força de condicionantes locais, teórico-metodológicos, e externos, do que se esperava de uma viagem científica, do que gostariam de ler os seus pares. Dessa forma, tem-se um conjunto de filtros que foram decisivos para a forma, a linguagem e, principalmente, a interpretação de seus relatos.

Eu me propunha a tornar útil essa viagem, com levantar uma carta desse rio, e recolher observações de todo gênero que tivesse ocasião de fazer num país tão pouco conhecido. As que respeitam os hábitos e costumes singulares das diversas nações que lhe habitam as margens seriam muito mais próprias a excitar a curiosidade de um grande número de leitores; porém eu acreditei que em presença de um público ao qual é familiar a linguagem dos físicos e geô- 
metras, não me era permitido versar matérias estranhas ao objetivo desta Academia (La Condamine (b), 41).

Os temas marcantes da produção de La Condamine acerca de sua descida pelo Amazonas, dizem respeito aos elementos naturais ou humanos que lhe exigiram trabalhos de relativa tradução, "novas plantas, novos animais e novos homens" ("new plants, new animals and new men”. Speake 18). Algumas vezes, utiliza a comparação quando lhe faltam termos adequados para a descrição, como quando fala sobre os nativos sul-americanos, indicando que são impropriamente chamados de "índios", sendo em realidade "trigueiros e de cor avermelhada, mais ou menos clara", e "insensíveis, devido ao número limitado de suas ideias" (La Condamine (b), p.1175-1199).

Partindo dessas indicações, é possível inferir uma tradução cultural em seus registros. De fato, como se pensar a tradução vinculada intrinsecamente a aspectos culturais? Ou melhor, como realizar a leitura de um processo tradutório que modifica signos para linguagens distintas? Ademais, cabe discutir a tradução em si e sua variante no campo cultural.

\section{Tradução Cultural, palavras e conceitos: La Condamine e suas ideias}

Cristina Marinetti chama a atenção da importância da chamada "virada cultural" nos Estudos da Tradução, afirmando que "Embora desenvolvida principalmente a partir do estudo da literatura, a abordagem cultural tem sido vista como perpassando a divisão literatura vs. não-literatura [...]. (Marinetti 26) ${ }^{3}$

Discussões recentes sobre a teoria e prática da tradução, sugerem que, quando emprestado ou compartilhado, o termo "tradução" se amplia ou se transforma como conceito. Para Blumczynski

3 "Although primarily developed from the study of literature, the cultural approach has been seen to cut across the literature v. non-literature divide [...]." (Marinetti 26).

Cad. Trad., Florianópolis, v. 40, n⿳0 2, p. 16-37, mai-ago, 2020. 
(2016), mais que um termo de plurissignificação, está sendo agora usado de forma genérica nos mais diferentes meios científicos. Ora, as ciências exatas, tanto quanto as humanidades, servem-se e ainda se servirão da contribuição do campo da tradução em seus estudos, mesmo em sua extensão e ensino. A abertura e aceitação do uso abrangente da tradução enquanto prática e conceito, revela a qualidade de ela ser ubíqua.

\begin{abstract}
A tradução nos leva a uma gama surpreendentemente ampla de territórios e nos confronta com a mais fundamental das questões. Ou, talvez, já esteja de alguma forma presente - como sugere o título deste livro -, muitas vezes com um nome diferente. Quando o complexo, rico, simultaneamente nômade e ubíquo - e, portanto, paradoxal - conceito de tradução é traduzido para outras áreas ou, mesmo, descoberto nelas, pode nos oferecer 'uma forma diferente de enfrentar as grandes questões epistemológicas do que sabemos e como sabemos'. (Blumczynski 9) ${ }^{4}$
\end{abstract}

Dessa forma, são abertos caminhos para se pensar numa tradução cultural, pois a preocupação conceitual ou de reafirmação de uma identidade estática e fechada dá lugar à busca da forma, ou seja, de como se pratica a tradução e por quais meios. Surge uma preocupação metodológica, que, por sua vez, se reflete em iniciativas de pensar a tradução em linhas de pesquisa antes vistas como distantes ou incapazes de dialogar interdisciplinarmente.

A tradução cultural apenas existe por um fenômeno inerente à espécie humana, que é social por natureza: o encontro com o

\footnotetext{
4 "Translation takes us into a surprisingly broad range of territories and confronts us with the most fundamental of questions. Or perhaps, it is already somehow present there-as suggested in the title of this book-often under a different name. When the complex, rich, simultaneously nomadic and ubiquitous-and therefore paradoxical-concept of translation is translated into other areas or indeed, discovered in them, it may offer us "a different way of facing the great epistemological questions of what we know and how we know" (Blumczynski 9).
} 
outro. Este encontro é muito mais que uma simples proximidade física, já que dele decorrem encontros étnicos, culturais, fenomenológicos, linguísticos, e outros, todos interligados e dependentes da diferença. Sobre a relação entre tradução e estudos antropológicos, Blumczynski (2016) destaca as abordagens que discutem as relações de poder no campo simbólico, por exemplo, onde o diálogo entre as diferenças se dá como num campo de força, com resistências e relaxamentos.

A tradução cultural poderia ser, então, explicada como o estudo dos fenômenos de tradução que se encontram no campo representacional, simbólico e cultural. Suas etapas se verificam tanto antes quanto depois da escrita de um texto. Pode-se citar o caso dos cronistas, em especial de La Condamine; por vezes seu texto está acompanhado de uma tradução idiomática; a tradução cultural se dá nas "entrelinhas".

À medida que observa, entra em contato com o diferente, registra e apresenta ao leitor, perpassa as etapas de tradução cultural, tendo de readequar, modificar ou até mesmo omitir partes do conteúdo. Seria, portanto, resultado do contanto com a diferença e o outro, consciente ou inconscientemente, direta ou indiretamente. No entanto, conforme dito anteriormente, o tradutor desenvolve um papel ativo, longe de ser um trabalho impessoal.

A necessidade de se fazer entender em campos linguísticos diferentes, com idiomas e entendimentos vários, fez com que La Condamine desenvolvesse um papel ativo, à medida que, com seu olhar de viajante estrangeiro, vislumbra em paradas amazônicas signos diferentes, mas que remetem a significados conhecidos no imaginário e arcabouço científico europeu. Por este motivo, constatamos que o autor desempenhou a função, ainda que desapercebida por ele próprio, de um tradutor. Com isto, falamos de uma tradução no campo dos fenômenos culturais, além da mais aparente que realizou, narrando os fatos amazônicos em francês.

A epistemologia encarregou-se, entre outras questões, de estudar minuciosamente o processo de percepção, concepção e formação das noções do conhecimento. Pensadores de diversa índole 
como Aristóteles, Bachelard, Cervo, Morin, Japiassu e outros, concordam num ponto: o de que o ser humano, enquanto ser dotado de inteligência e percepção da existência, relaciona-se com o mundo através dos sentidos, que lhe põem em contato com o lado externo da consciência. Dito isto, vemos que, logo no primeiro contato com a realidade externa, La Condamine, enquanto indivíduo dotado de sentidos, traduz automaticamente os estímulos a formulações mentais primárias: uma tradução do mundo.

Em segundo lugar, temos o autor no processo de formatação das ideias, onde o imaterial é codificado em forma material, com a escrita. Durante este processo, deve escolher os códigos que considera apropriados para representar suas ideias, neste caso em língua francesa. E, em decorrência do contato de leitores que devem decodificar, ou seja, ler os registros, podemos considerar pelo menos três principais etapas de tradução, que transitam entre os âmbitos linguístico e cultural.

\begin{abstract}
Qual é exatamente a relação entre viagem e tradução? Algumas respostas se sugerem prontamente. $\mathrm{O}$ viajante deve traduzir a fim de dar sentido a lugares e pessoas estrangeiras. Por outro lado, o conhecimento de outras línguas além da própria pode fazer com que se queira viajar a fim de usar idiomas em seus ambientes nativos. E se o que se entende por tradução é a relocalização de uma mensagem de uma língua para outra, então toda viagem - a relocalização de uma pessoa de um lugar para outro - não é também um tipo de tradução? (Di Biase 9)
\end{abstract}

\footnotetext{
5 "What exactly is the relationship between travel and translation? Some answers suggest themselves readily. The traveler must translate in order to make sense of foreign places and foreign people. On the other hand, a knowledge of languages other than one's own might make one want to travel in order to put those languages to use in their native settings. And if what is meant by translation is the relocation of a message from one language to another, then is not all travel - the relocation of a person from one place to another - also a kind of translation? (Di Biase 9).
} 
Outro importante fator que diretamente gera consequências na prática de se registrar literariamente, considerando-se a ocorrência da tradução cultural, é o contexto sociocultural e das relações ideológicas no período em que o autor escreve. A expedição de La Condamine pode ser considerada como um verdadeiro triunfo diplomático da comunidade científica europeia (Pratt). E não apenas dos cientistas franceses, mas também da coroa espanhola, levando-se em consideração que, com o ato de "proteger" a expedição, havia o intuito de se "limpar" a imagem da crueldade praticada pelos espanhóis em suas então colônias. Assim, a cooperação entre diferentes países sob a égide da ciência pôde até mesmo arrefecer intensas rivalidades.

O resultado dessa expedição, publicado em três volumes, foi considerado um verdadeiro sucesso literário. Parte desse sucesso poderia ser explicado pela facilidade com que La Condamine parece demonstrar em transpor para o francês e o latim boa parte do que observou em terras sul-americanas, com destaque para a sua famosa descida pelo Rio Amazonas. Sua narrativa traz exemplos do fazer da tradução cultural.

Ao trazer à lembrança o posicionamento expresso pelo cronista francês, pode-se notar que, apesar de seus esforços para não se assemelhar aos "viajantes curiosos" da época, que de forma sensacionalista divulgavam estórias mágicas e intrigantes, o autor não pôde se desvencilhar totalmente do desejo que o impelia a registrar as formas de vida e organização social com as quais se deparava. Assim, deixou em seu relato, especialmente quando escreveu sobre a descida pelo Rio Amazonas, ricas descrições da fauna, flora e dos povos indígenas, todos traspassados pela prática da tradução cultural.

Ainda não falei dos peixes singulares, que se descobrem no Amazonas, nem das diferentes espécies de animais raros que se veem nas suas margens. Este título sozinho forneceria assunto para a obra, e tal estudo pediria uma viagem especial, e um viajante que não tivesse outra ocupação (La Condamine (b), 103). 
Ao falar do peixe-boi ou "vaca-marinha" (não confundir com foca em língua francesa, veau marin), refere-se a ele como sendo "o maior dos peixes d'água doce conhecidos" (LA Condamine (b),103); na realidade, trata-se de um mamífero. Chama de "lampreia" o peixe hoje conhecido como poraquê, espécie elétrica que produz uma descarga capaz de atormentar e até matar as presas.

Para La Condamine, os jacarés eram "crocodilos", e seu maior predador o "tigre", como chamou a onça. Curiosa também é a forma como nomeia uns supostos "alces", na realidade antas ou tapires, característicos do ambiente amazônico. Aqui, vê-se não apenas a tentativa de nomear as espécies que seus sentidos apreendiam, mas também de encontrar termos existentes em francês.

Outra dificuldade que o viajante encontrava era a ausência em sua língua materna de palavras que apresentassem significado igual ou semelhante aos significantes aos quais pretendia fazer referência. Nesses casos, o autor passa a utilizar a nomenclatura corrente entre os habitantes amazônicos.

Os índios de Chuchunga não tinham mais que pequenas canoas, próprias para o uso que delas fazem, e a que eu havia mandado buscar em Santiago por um próprio não podia chegar antes de quinze dias. Encarreguei o cacique de mandar fazer-me pelos seus homens uma jangada ou balsa (é o nome que dão no país a essa embarcação e à madeira de que ela se faz), e a pedi tão grande, que me coubesse com todos os instrumentos e bagagens (La Condamine (b), 52).

Outras passagens fazem referência à diferença de práticas culturais e econômicas, que causam estranhamento ao autor, já que a França, assim como outras grandes economias da Europa, havia conquistado sua soberania político-econômica através do acúmulo de tesouro, seja do Estado (monarquias à época) ou de bens monetários privados. Há, portanto, grande surpresa ao constatar que alguns grupos indígenas ignoravam ou se recu- 
savam a defender o lucro, o acúmulo de bens supérfluos ou a propriedade privada.

No entanto, um expresso que eu enviara a Tomependa, com
ordens do governador de Jaén ao seu lugar-tenente de San-
tiago, para me enviar uma canoa ao porto, atravessara todos
os obstáculos em uma pequena jangada feita de dois ou três
pedaços de madeira, o que basta a um índio nu e excelente
nadador, como todos os são [...]. Nesse trecho o rio recebe
do norte várias torrentes que, no tempo das grandes chuvas,
carreiam uma areia misturada de palhetas e grãos de ouro.
Os índios vão recolher, então, precisamente a quantidade
necessária para pagar o tributo ou capitação, e somente o
fazem quando estão muito solicitados a pagá-lo. O resto do
tempo eles calcariam o ouro debaixo dos pés, em vez de se
darem o trabalho de o recolher e triar. Em toda essa zona,
as duas margens do rio estão cobertas de cacau selvagem,
que não é menos bom que o cultivado, e de que os índios
não fazem tampouco o menor caso (La Condamine (b), 51).

Em seus relatos, há trechos onde se pode ver claros contrastes onde, ora apresenta aprovação ou ânimo frente ao contexto, ora um sentimento de aflição. Pode-se dar como exemplo as descrições de alguns povoados e o comportamento de seus habitantes:

Em São Paulo [de Olivença] começamos a ver, em lugar de casas e igrejas de bambu, capelas e presbitérios de pedra, de terra e tijolo, e muros alvejados com asseio. Fomos ainda agradavelmente surpreendidos por ver, no meio daqueles desertos, camisas de pano de Bretanha sobre todas as mulheres índias, malas com fechaduras e chaves de ferro em suas casas, e por achar aí agulhas e pequenos espelhos, facas, tesouras, pentes, e diversos outros utensílios da Europa, que os índios obtêm todos os anos no Pará, nas viagens que fazem até lá para levar o 'cacau', que eles 
colhem sem nenhuma cultura pelas margens do rio (La Condamine (b), 76).

Para La Condamine "a natureza parece ter favorecido a preguiça dos índios, e ter ultrapassado suas necessidades (105). Não é de se espantar que os diferentes modos de vida dos povos amazônicos, adaptados ao seu contexto ambiental e cultural, de contrastes gritantes com aquele observado na Europa do século XVIII, produzissem não apenas na subjetividade do autor, mas nas palavras que se preservaram, um olhar etnocêntrico, decorrente da diferença cultural.

Se estes reproches não dissessem respeito senão aos índios do Peru, aos quais não falta senão o nome de escravos, poder-se-ia crer que essa espécie de embrutecimento nasce da servilidade em que vivem [...]. Mas os índios das missões e os selvagens que gozam de liberdade são tão limitados por não dizer tão estúpidos quanto os outros, e não se pode ver sem humilhação o quanto o homem abandonado à natureza, privado de educação e sociedade, pouco difere das bestas (La Condamine (b), 60).

Outro exemplo, não menos importante, pode ser dado quando de suas colocações acerca do "estado de ignorância" dos povos indígenas. Diz ele: "sei bem que todos, ou quase todos os índios da América meridional são mentirosos, crédulos, encasquetados com o maravilhoso (La Condamine (b), 84). Ora, sendo o autor estudioso membro da Académie des Sciences de Paris vindo em longa missão de estudos, ao deparar-se com grupos populacionais, em sua maioria de indígenas, com pouca ou nenhuma instrução formal (às vezes com ensino religioso cristão), viu-se num ambiente onde a ciência que conhecia era praticamente inexistente.

Essa distância entre o conhecimento científico e empírico-popular, entretanto, não o impediu de utilizar grande número de contribuições dos locais, dos quais empregou nomes, explicações so- 
bre a geografia e a história da região, ajuda para se deslocar num ambiente novo, entre outras. Dessa forma, pode-se interpretar as peculiares colocações, das quais alguns exemplos foram citados, como indicativos da tradução cultural realizada pelo cronista francês em sua passagem pela Amazônia.

\section{Considerações finais}

Apesar de toda a carga etnocêntrica desenvolvida e utilizada pelo naturalista La Condamine, seus relatos mostram uma vasta percepção cultural amazônica, na qual se aclara a diversidade de inúmeras populações indígenas que já desapareceram, sendo poucas as que conseguiram transcender, com suas táticas de resistência, ao domínio do "homem branco".

Os recentes estudos (Oliveira Filho; Roosevelt) revelam que o atual modo de vida dos habitantes remanescentes dos que aqui viviam é consequência direta de fatores propiciados pela chamada "conquista europeia", ou melhor traduzida, pela expansão e ocupação do território amazônico entre os séculos XVI e XVIII, tais como: queda da densidade populacional, eliminando a necessidade de exploração do solo; o fato dos europeus terem se apoderado das melhores áreas, afastando assim os indígenas para as áreas interfluviais, sem esquecer da desarticulação dos complexos político e militar dos nativos, que tiveram de se submeter a numerosas transmigrações (Gomes; Kern; Sampaio).

Por outro lado, cabe questionar a importância do olhar, num momento único e oportuno, traduzido a partir de inúmeras lentes, registrado através das crônicas de viajantes, e La Condamine não foge a esta regra. Se, por um lado, essa população e seu território estavam vivenciando ou experenciando um processo latente e violento de etnocídio, extermínio, desagregação social e perda de território, por outro, vivia num contexto de agregações forçadas e criação de uma nova sociedade gestada através do processo colonial. 
Em se tratando da Amazônia e dos povos da floresta, é importante ressaltar a importância desse bioma e de seu conjunto etnográfico; no sentido de cooperar na corrida pelas respostas às delicadas situações e dificuldades que a região vem atravessando ao longo dos anos, bem como a luta pelos direitos inalienáveis das populações da floresta que ainda resistem, assim como no resgate de uma História mais próxima das realidades vivenciadas por estas e que ainda esperam por pesquisas apropriadas. Dentre as que lançam novos caminhos de compreensão, está a tradução cultural aqui apresentada.

Esse conjunto histórico corre o risco de se perder ou ficar cada vez mais empobrecido. Portanto, antes de tudo, torna-se urgente triar les idées para poder viajar par le voyageur et à travers la rivière.

\section{Referências}

Aguiar, J. V. S. "As narrativas dos viajantes e a produção dos povos indígenas". In: Congresso de Leitura do Brasil. Campinas, 2009, p. 155-163.

Blumczynski, Piotr. Ubiquitous translation. New York: Routledge, 2016.

Buffon, Conde de. Histoire naturelle de l'homme. Ed. Jean Piveteau. Paris: PUF, 1954.

Clastres, Hélène. Primitivismo e ciência do homem no século XVIII. Discurso, $\mathrm{n}^{0} 13,1980$, p. 187-208.

Di Biase, Carmine G. (Ed.). Travel and Translation in the Early Modern Period. Amsterdam/New York: Rodopi, 2006. 
Gennep, Arnold Van. Religions, moeurs et légendes. Paris: Mercure de France, 1914.

Gomes, Flavio dos Santos. "Migrações, populações indígenas e etno-genese na América Portuguesa (Amazônia Colonial, séc.XVIII)". Nuevo Mundo-Mundos Nuevos. (2011): 1-21.

Kern, Arno Alvarez (a). Fronteiras culturais, impactos e contatos. Estudos iberoamericanos, 2000.

Kern, Arno Alvarez (b). "Fronteira/fronteiras: conceito polissêmico, realidades complexas. Revista História e Diversidade, v. 8, (2016): 10-14.

La Condamine, C. M. de (a). Relation abrégée d'un voyage dans l'intérieur de l'Amérique méridionale, depuis la côte de la mer du Sud jusqu'aux côtes du Brésil et de la Guiane, en descendant la rivière des Amazones - Lue à l'assemblée publique de l'Académie des Sciences, le 28 avril 1745 - avec une carte du Maragnon ou de la rivière des Amazones, levée para le même. Paris: chez la Veuve Pissot, in-8 ${ }^{\circ}$, XVI, 216p., 1745.

La Condamine, C. M. de (b). Viagem na América Meridional descendo o rio das Amazonas. Tradução da Comissão do Projeto Coleção o Brasil visto por estrangeiros. Brasília: Senado Federal, 2000. Disponível em: em https:// www2.senado.leg.br/ bdsf/bitstream/handle/id/1045/580837.pdf?sequence=4\&isAllowed=y. Acesso em: 20/10/2019.

Marinetti, Cristina. "Cultural Approaches". In: Gambier, Yves; Doorslaer, Luc van. Handbook of Translation Studies. Vol. 2. Amsterdam/Philadelphia: Routledge, 2011, p. 26-30.

Mcconnell, Anita. "La Condamine's Scientific Journey down the River Amazon, 1743-1744”. Annals of Science, 48 (1991), 19 p.

Oliveira Filho, João P. "Formas de dominação sobre o indígena na fronteira amazônica: Alto Solimões, de 1650 a 1910". Cadernos do CRH (UFBA), v. 25, (2012): 17-32. 
Pratt, Mary Louise. Imperial eyes: travel writing and transculturation. $2^{\mathrm{a}}$ ed. New York/Oxon: Routledge, 2008.

Roosevelt, Anna C. "Prehistory of Amazonia". In: Renfrew, Colin; Bahn, Paul (Ed.). Cambridge World Prehistory. Cambridge, UK: Cambridge University Press (2013).

Sampaio, Patrícia M. M. Espelhos Partidos: etnia, legislação e desigualdade na Colônia. $1^{\mathrm{a}}$ ed. Manaus: EDUA/FAPEAM, 2012.

Speake, Jennifer (Ed.). Literature of travel and exploration - an encyclopedia. Vol. I. London and New York: Routledge, 2013.

Recebido em: 04/12/2019 Aceito em: 12/03/2020 Publicado em maio de 2020

Samuel Lucena de Medeiros. E-mail: samuca slm@hotmail.com. ORCID: https://orcid.org/0000-0002-0455-5877

Tatiana de Lima Pedrosa Santos. E-mail: tatixpedrosa@yahoo.com.br. ORCID: https://orcid.org/0000-0001-5772-4331

Walter Carlos Costa. E-mail: walter.costa@gmail.com. ORCID: https://orcid. org/0000-0001-5853-0950 